\title{
Microsurgical third ventriculocisternostomy as an alternative to ETV: report of two cases
}

\author{
Erik J. van Lindert
}

Received: 10 August 2007 /Revised: 2 October 2007 / Published online: 18 January 2008

(C) The Author(s) 2008

\begin{abstract}
Objective To describe a microsurgical alternative to endoscopic third ventriculocisternostomy.

Methods Two children with shunt-dependent hydrocephalus and multiple shunt revisions were considered candidates for third ventriculocisternostomy (TVS). Because of slit ventricles, an endoscopic approach was not possible and, therefore, both patients received a microsurgical TVS by a supraorbital approach.

Results In both cases, microsurgical TVS was successful and the patients became shunt free.

Conclusion Microsurgical TVS by a supraorbital craniotomy is a viable alternative to endoscopic TVS in selected cases.
\end{abstract}

Keywords Microsurgery · Neuroendoscopy ·

Supraorbital approach - Third ventriculocisternostomy .

Lamina terminalis $\cdot$ Minimally invasive

\section{Introduction}

In the last two decades, endoscopic third ventriculocisternostomy (ETV) via a precoronal burr hole and transfrontal approach became a good therapeutic alternative to shunt placing and in non-communicating hydrocephalus, ETV has become the first choice of treatment [29]. Also, ETV is more and more offered to patients with shunt at the time of shunt malfunction or in case of slit-ventricle syndrome (SVS) as a means to become shunt independent. However, in a

\section{E. J. van Lindert $(\square)$}

Department of Neurosurgery,

Radboud University Nijmegen Medical Center,

P. B. 9101,

6500 Nijmegen, The Netherlands

e-mail: e.vanlindert@nch.umcn.nl subpopulation of patients, ETV is technically not feasible due to small ventricular system or slit ventricles. Patients with such small ventricles and multiple shunt malfunctions possess a highly therapeutic challenge.

Other means of internal shunting, as an alternative to ventriculoperitoneal or ventriculoatrial shunting, have been described in the decades before ETV became a routine procedure. Third ventriculocisternostomy (TVS) has been performed by subtemporal craniotomy [5], anterior subfrontal approach [6, 7, 24], Torkildsen ventriculocisternostomy [26, 27], microsurgical ventriculocisternostomy [17, 20], stereotactic ventriculocisternostomy [4, 13, 19], fluoroscopic ventriculocisternostomy [10-12], microsurgical opening of the lamina terminalis [21], reconstruction of or stent placement in the aqueduct [15], and endoscopic aqueductoplasty [22].

TVS by lamina terminalis fenestration is still a routine procedure in aneurysm surgery for subarachnoid hemorrhage, especially in case of anterior communicating artery aneurysms. However, the possibility of a microsurgical TVS (MTV) for obstructive hydrocephalus seems to be lost to oblivion by the widespread use of ETV.

In this report, we describe two patients in whom an ETV could not be performed because of slit ventricles and who became shunt independent after MTV by a minimally invasive supraorbital approach.

\section{Case reports}

\section{Case 1}

This eight-year-old boy was born with an occipital meningocele and a thoracolumbar myelomeningocele. Both of these congenital abnormalities were operated upon 1 day after birth. Within several days, the patient developed a hydrocephalus 
which was treated with a ventriculoperitoneal shunt. One month later, a Chiari type II malformation was treated by a suboccipital craniotomy and a duraplasty. Since then, the patient experienced multiple drain infections and both proximal and distal drain dysfunctions. Ventriculoperitoneal shunting and ventriculoatrial shunting with different types of valves were implanted but none of them led to problem-free shunting, largely due to stiff slit ventricles. In March 2003, the patient experienced another drain dysfunction with an intracranial pressure (ICP) of $50 \mathrm{~cm} \mathrm{H}_{2} \mathrm{O}$ while maintaining slit ventricles followed by infection necessitating external ventricular drainage and antibiotics treatment. In search for a more definitive treatment of his recurrent drain dysfunctions, we considered to perform an ETV. However, the very narrow slit-like lateral ventricles and third ventricle did not allow a safe execution of this procedure (Fig. 1a-c). As an alternative, a microsurgical fenestration of the lamina terminalis and Liliequist's membrane was performed via a right-sided eyebrow incision and a small supraorbital craniotomy (Fig. 2). The postoperative course was uneventful. The patient did not experience any symptoms suspect for hydrocephalus or raised intracranial pressure during a follow-up of 3 years. MRI control examination did not reveal a significant increase in the size of the ventricular system (Fig. 1d-f).

\section{Case 2}

This 16-year-old boy, born with a lumbosacral meningocele and shunt dependent from birth on, developed with 13 years of age an increasing overdrainage syndrome with positional headaches. In another hospital, many valve revisions were performed in order to solve this problem and to rule out underdrainage. The original differential pressure valve was exchanged over a period of 3 years for several different Delta valves and a Codman Medos programmable valve, with which practical all settings were tried. Also, a shunt explantation was tried but after initial improvement, this led to a secondary increase of headaches and papilledema within several weeks, after which again, a Codman Medos valve was inserted. From this procedure, we obtained the security that the patient was still shunt dependant at that age. A new ICP monitoring was performed in the other hospital which showed negative intracranial pressures in upright sitting position and an ICP of $5-10 \mathrm{~cm} \mathrm{H}_{2} \mathrm{O}$ in the supine position. The headache continued, even seemed to increase and became also chronic with positional increase of headaches in the upright position. The largest problem, however, became the frequent absenteeism from school because of these headaches. Chronic consultation of a pediatric neurologist and conservative treatment measures did not alter the symptoms either.

At this time, he was referred to our department. As a first measure, a PaediGav 9/29 gravitational valve was applied because we had gained good experience with this type of valve but without any positive effect on the headaches. Although the patient did not improve after many shunt upgrading, it was felt that his headaches most likely were to be attributed to chronic overdrainage. Therefore, we sought for a means to have the patient shunt independent (after
Fig. 1 Case report 1. a, b Axial T1 MRI depicting very small slit-like lateral and third ventricles, c sagittal T2 MRI showing small third ventricle and lamina terminalis, $\mathbf{d}$, e postoperative axial T1 MRI showing minimal increase in size of the lateral ventricles; f postoperative sagittal T2 MRI shows a minimal increase of the third ventricle, but no flow void phenomenon at the lamina terminalis
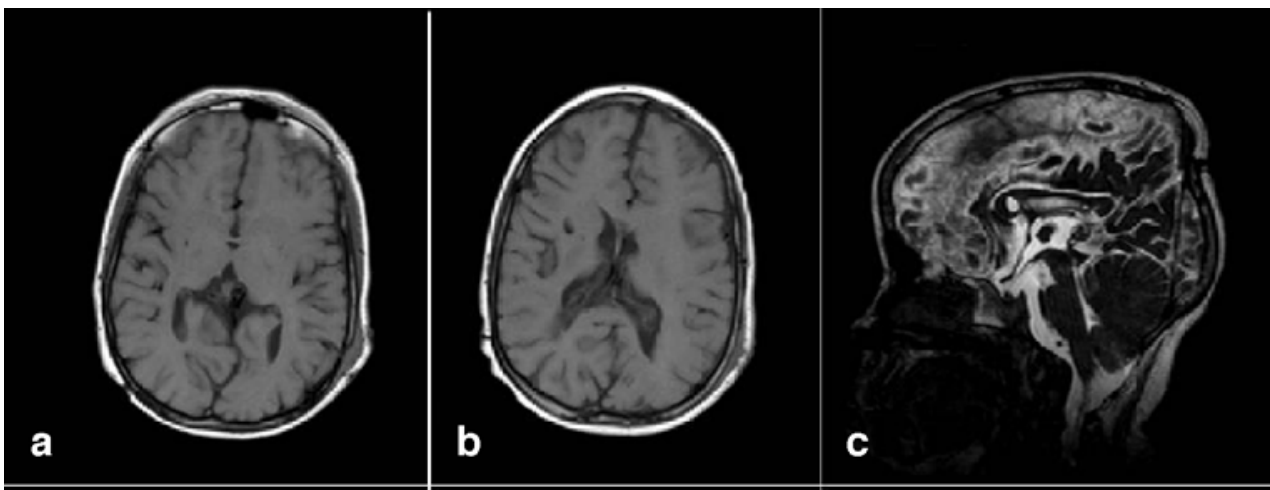

\section{b}

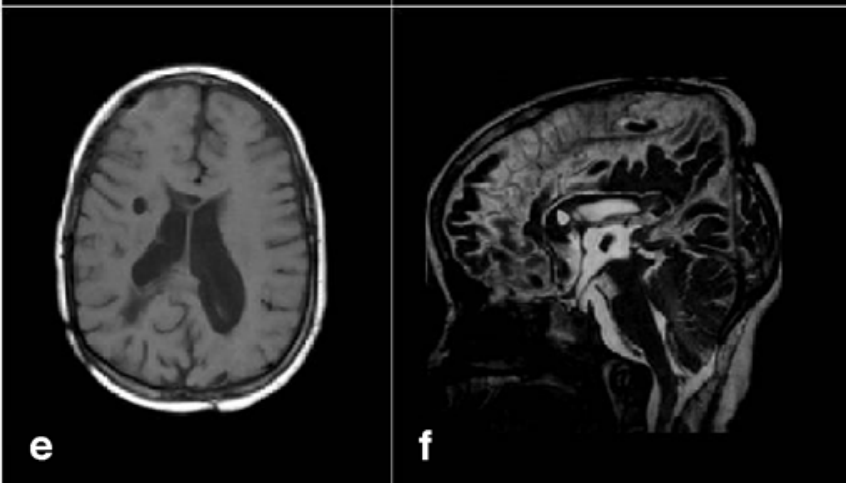




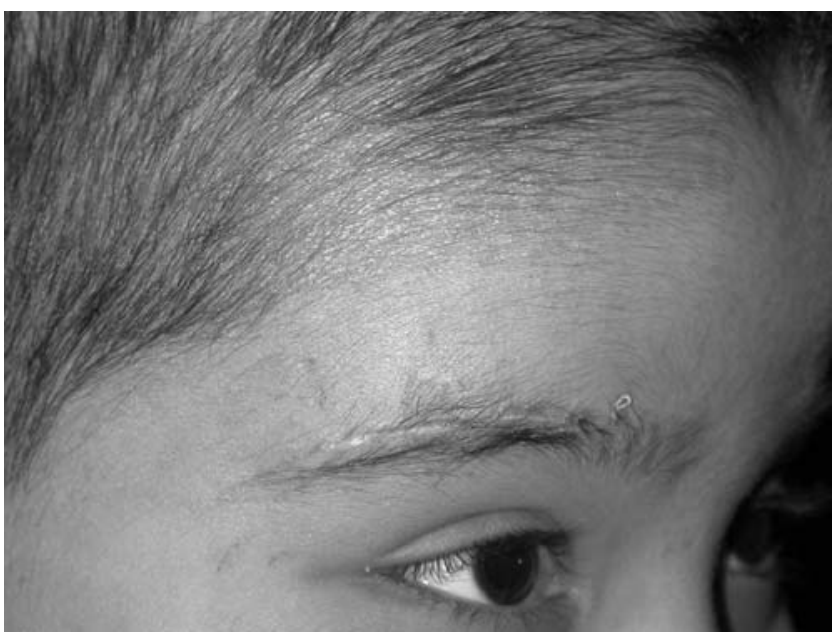

Fig. 2 Postoperative photograph of case 1 showing the hardly visible scar of the eyebrow incision

proven shunt dependency at the time). Because an ETV was considered to be impossible, a right supraorbital craniotomy with a lamina terminalis fenestration and fenestration of Liliequist's membrane was executed and the shunt was completely removed, except for the ventricular catheter that was fixated and therefore left behind. Again, no significant change of the headache could be observed. A 24-h continuous ICP monitoring, performed after 6 weeks because of unchanged symptoms, revealed a normal ICP in supine and upright positions with a maximum nightly increase to $13 \mathrm{~mm} \mathrm{Hg}$. Two years after surgery, the patient is still shunt independent with chronic headaches, no papilledema (contrary to the first shunt explantation before MTV), and in a rehabilitation program. A computed tomography (CT) scan 1.5 years after surgery shows a minimal increase in the size of the ventricles (Fig. 3).

\section{Discussion}

There are many complications related to shunt dependency. In $10.9-29 \%$ of cases complications (other than mechanical obstruction) occur, the majority of which is a shunt infection [9, 14, 18]. Mechanical complications in shunts including late shunt malfunction may even occur in up to $45.9 \%$ in the first postoperative year and up to $81 \%$ of patients at 12 years follow-up [8, 9, 18]. Also, the longterm shunt-related mortality rate of the shunt-treated patient, despite many improvements in shunt technique, diagnostics, and follow-up, remains high $(2.9 \%$ to $12.4 \%$ at 10 years follow-up) $[10,16,30]$. Therefore, the ultimate goal in hydrocephalus therapy is to get the patient shunt free.

Since the first experience by Guiot [10], transcortical or transventricular endoscopic third ventriculocisternostomy has proved to be a valid alternative in the treatment of

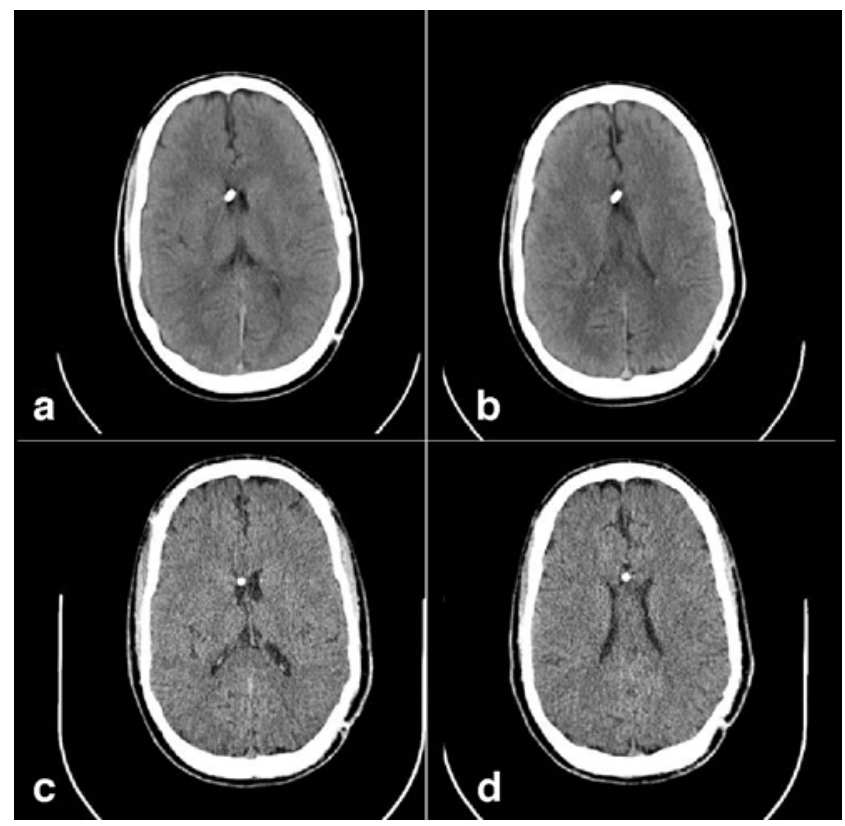

Fig. 3 Case report 2. a, b Preoperative CT scan depicting slit-like ventricles; c, d postoperative CT scan with minimal increase of ventricle size and a residual ventricular catheter that could not be removed

obstructive hydrocephalus. Also, several studies have shown that ETV is an effective treatment in patients with obstructive hydrocephalus who had undergone previous shunting procedures $[1,23,25]$. It can provide a definitive cure for patients with difficult-to-manage shunt dysfunction.

The potential advantages of ETV over conventional shunting are clear. However, ETV requires a certain degree of lateral and third ventricle dilatation to be performed safely. In case of small ventricles, the potential risks of this procedure (injuring fornix, thalamostriate or internal cerebral veins, hypothalamus) outweigh the advantages. One might consider to enlarge the ventricles and, thus, to facilitate an ETV. This has been safely and successfully performed by Butler and Khan [2] with an external ventricular drain and by Chernov et al. [3] by using a programmable valve of which the pressure was increased in a stepwise fashion. In our department, we have practised both techniques for ventricular dilatation successfully, but we also encountered serious complications from this strategy.

In both cases described here, we already knew from previous shunt malfunctions that the ventricles hardly dilate with increased intracranial pressure. A shunt revision in case 1 for proximal catheter obstruction only several months before the MTV revealed an intracranial pressure of $50 \mathrm{~cm} \mathrm{H}_{2} \mathrm{O}$ with only minimal ventricular dilatation. Therefore, in our two patients, we opted to perform an open microsurgical TVS by opening the lamina terminalis via a small supraorbital craniotomy and did not consider 
achieving ventricular expansion. Both patients became shunt independent.

Open surgical TVS once was a popular therapeutic technique for the treatment of obstructive hydrocephalus before the advent of VP shunt systems. The idea of third ventricular communication into the chiasmatic cisterns was initially proposed by Dandy [7] in 1922 as a surgical procedure to alleviate obstructive hydrocephalus. It was first performed by Dandy via a subfrontal approach and frequently required the sacrifice of one optic nerve and elevating the chiasm. Later, Dandy [5] described the alternative subtemporal approach.

In 1936, Stookey and Scarff [24] described a subfrontal anterior approach for TVS through the lamina terminalis and the hypothalamus to the lumen of the third ventricle. Scarff [21] published a review of 527 patients subjected to this operation by both the subfrontal and subtemporal procedures, as reported by many authors. The over-all operative mortality was $15 \%$ and the permanent arrest of the hydrocephalus was obtained in $70 \%$ of the survivors.

Open surgical TVS for obstructive hydrocephalus was then abandoned due to better and reliable shunting systems and because the advent of endoscopic techniques of this procedure is not reported to be in widespread use. Nevertheless, it remained a routine procedure during aneurysm surgery in order to get more slack ventricles and to prevent, or decrease the number of, posthemorrhagic hydrocephalus. To the best of our knowledge, MTV, by opening the lamina terminalis for the treatment of hydrocephalus, was last reported in 1988. In this report from Reddy et al. [17], five shunted patients with aqueduct stenosis and slit ventricle syndrome described are treated successfully with MTV via opening of the lamina terminalis. The lamina terminalis was approached in all patients via a classic pterional craniotomy. Since then, reports on ETV dominate the literature.

\section{Operative technique}

Many neurosurgeons consider craniotomy and MTV too large and risky a procedure. However, the procedure described in this report is a truly minimally invasive procedure. The operation time is about $1 \mathrm{~h}$, the wound and scar are minimal, recuperation is very fast, and the potential risks are very low. One might even suggest that this procedure is safer than an ETV because it has an extracerebral approach, in contrast to ETV, and that surgery is better controlled with more opportunities for hemostasis.

The supraorbital craniotomy with eyebrow incision has been described previously [28]. The Sylvian fissure needs not to be dissected. The ipsilateral optic nerve and the optic chiasm, the ICA and the ipsilateral ACA as well as the ACoA are exposed after which the lamina terminalis is reached. Lamina terminals fenestration is a standard procedure easily performed with the bipolar forceps or an arachnoid diamond knife. This, however, is not sufficient. It is essential to open Liliequist's membrane to allow free and sufficient CSF communication between the posterior fossa and the suprasellar and frontobasal cisterns.

Recovery of this operative procedure is fast and without major side-effects. Usually, hospitalization time is 2 to 3 days.

\section{Conclusion}

In conclusion, open microsurgical third ventriculocisternostomy by opening the lamina terminalis should be kept in mind as an alternative technique for treating patients with multiple shunt failures and small ventricles not accessible for an endoscopic approach in an effort to make these patients shunt independent.

Open Access This article is distributed under the terms of the Creative Commons Attribution Noncommercial License which permits any noncommercial use, distribution, and reproduction in any medium, provided the original author(s) and source are credited.

\section{References}

1. Boschert J, Hellwig D, Krauss JK (2003) Endoscopic third ventriculostomy for shunt dysfunction in occlusive hydrocephalus: long-term follow up and review. J Neurosurg 98:1032-1039

2. Butler WE, Khan SA (2001) The application of controlled intracranial hypertension in slit ventricle syndrome patients with obstructive hydrocephalus and shunt malfunction. Pediatr Neurosurg 35:305-310

3. Chernov MF, Kamikawa S, Yamane F, Ishihara S, Hori T (2005) Neurofiberscope-guided management of slit-ventricle syndrome due to shunt placement. J Neurosurg 102:260-267

4. Dalrymple SJ, Kelly PJ (1992) Computer-assisted stereotactic third ventriculostomy in the management of noncommunicating hydrocephalus. Stereotact Funct Neurosurg 59:105-110

5. Dandy W (1945) Diagnosis and treatment of strictures of the aquaduct of Sylvius (causing hydrocephalus). Arch Surg 51:1-4

6. Dandy W (1920) The diagnosis and treatment of hydrocephalus resulting from strictures of the aquaduct of Sylvius. Surg Gynaecol Obstet 31:340-358

7. Dandy W (1922) Treatment of non-encapsulated brain tumors by extensive resection of contiguous brain tissue. IV an operative procedure for hydrocephalus. Johns Hopkins Hosp Bull 33:189-190

8. Devaux BC, Joly LM, Page P, Nataf F, Turak B, Beuvon F, Trystram D, Roux FX (2004) Laser-assisted endoscopic third ventriculostomy for obstructive hydrocephalus: technique and results in a series of 40 consecutive cases. Lasers Surg Med 34:368-378

9. Greenberger R, Khangure MS, Chakera TM (1987) The morbidity of CT air meatography: a follow-up of 84 patients. Clin Radiol $38: 535-536$

10. Guiot G (1973) Ventriculo-cisternostomy for stenosis of the aqueduct of Sylvius. Puncture of the floor of the third ventricle 
with a leucotome under television control. Acta Neurochir (Wien) 28:275-289

11. Guiot G, Derome P, Hertzog E, Bamberger C, Akerman M (1968) Ventriculo-cisternostomy under radioscopic control for obstructive hydrocephalus. Presse Med 76:1923-1926

12. Hirsch JF, Hirsch E, Sainte RC, Renier D, Pierre-Khan A (1986) Stenosis of the aqueduct of Sylvius. Etiology and treatment. J Neurosurg Sci 30:29-39

13. Hoffman HJ, Harwood-Nash D, Gilday DL (1980) Percutaneous third ventriculostomy in the management of noncommunicating hydrocephalus. Neurosurgery 7:313-321

14. Koch D, Wagner W (2004) Endoscopic third ventriculostomy in infants of less than 1 year of age: which factors influence the outcome? Childs Nerv Syst 20:405-411

15. Leksell L (1949) A surgical procedure for atresia of the aqueduct of Sylvius. Acta Psychiatr Neurol Scand 24:559-568

16. Meier U (2003) [Shunt operation versus endoscopic ventriculostomy in normal pressure hydrocephalus: diagnostics and outcome]. Zentralbl Neurochir 64:19-23

17. Reddy K, Fewer HD, West M, Hill NC (1988) Slit ventricle syndrome with aqueduct stenosis: third ventriculostomy as definitive treatment. Neurosurgery 23:756-759

18. Rohde V, Gilsbach JM (2000) Anomalies and variants of the endoscopic anatomy for third ventriculostomy. Minim Invasive Neurosurg 43:111-117

19. Sayers MP, Kosnik EJ (1976) Percutaneous third ventriculostomy: experience and technique. Childs Brain 2:24-30

20. Scarff JE (1935) Third ventriculoscopy as the rational treatment of obstructive hydrocephalus. J Pediatr 6:870-871
21. Scarff JE (1966) Third ventriculostomy by puncture of the lamina terminalis and the floor of third ventricle. J Neurosurg 24:935-943

22. Schroeder HW, Oertel J, Gaab MR (2004) Endoscopic aqueductoplasty in the treatment of aqueductal stenosis. Childs Nerv Syst 20:821-827

23. Siomin V, Weiner H, Wisoff J, Cinalli G, Pierre-Kahn A, Saint-Rose C, Abbott R, Elran H, Beni-Adani L, Ouaknine G, Constantini S (2001) Repeat endoscopic third ventriculostomy: is it worth trying? Childs Nerv Syst 17:551-555

24. Stookey B, Scarff J (1936) Occlusion of the aquaduct of Sylvius, by neoplastic and non-neoplastic processes with a rational surgical treatment for relief of the resultant obstructive hydrocephalus. Bull Neurol Inst New York 5:348-377

25. Teo C, Jones R (1996) Management of hydrocephalus by endoscopic third ventriculostomy in patients with myelomeningocele. Pediatr Neurosurg 25:57-63

26. Torkildsen A (1939) New palliative operation in cases of inoperable occlusion of the sylvian aquaduct. Acta Psychiatr Neurol Scand 82:117-123

27. Torkildsen A (1960) A follow-up study 14 to 20 years after ventriculocisternostomy. Acta Psychiatr Scand 35:113-121

28. van Lindert E, Perneczky A, Fries G, Pierangeli E (1998) The supraorbital keyhole approach to supratentorial aneurysms: concept and technique. Surg Neurol 49:481-489

29. van Lindert EJ, Beems T, Grotenhuis JA (2006) The role of different imaging modalities: is MRI a conditio sine qua non for ETV. Childs Nerv Syst 22:1529-1536

30. Yadav YR, Pande S, Raina VK, Singh M (2004) Lumboperitoneal shunts: review of 409 cases. Neurol India 52:188-190 